\title{
THE USE AND APPLICATION OF VECTOR OPTIMISATION METHODS FOR LAND USE AND TRANSPORTATION INTEGRATION
}

\author{
ILSE MARIA SCHOEMAN \\ North-West University (Potchefstroom), South Africa
}

\begin{abstract}
The aim of this chapter is to use vector optimisation methods to create a user-friendly scorecard to measure on a local municipality level the outcomes of integration between land use and transport. The development and application of a scorecard inspires continuous assessment and improvement of services to determine the weak and strong points of each local municipality. Thereby, supporting decision making to intervene earlier at local municipalities which perform poorly. This will be done by a detailed discussion of an "improved" Saaty's method and an "improved" row geometric mean method to derive the relevant weights of the criteria and factors. Furthermore, by using two analytical processes (i.e. weighted sum process and the exponential weighted process) the ranking of the different local municipalities' performance can then be determined. From this application the level of integration between land use and transportation systems can be scientifically calculated.
\end{abstract}

Keywords: weights, scorecard, vector optimisation, multi-objective optimisation, multi-criteria analysis.

\section{INTRODUCTION}

Vector optimisation i.e. multi-objective optimisation, is the process used to optimise a set of objective functions of Marler et al. [1]. These concepts develop from the following areas:

- pure mathematics

- economic (welfare and equilibrium) theories

- game theory.

The solution of a vector optimisation problem is called a Pareto optimal set (i.e. a set of points). The multi criteria analysis (MCA) process, which is a special case of the general vector optimisation process, is based on a hierarchical aggregation procedure combined with an analysis function (like the linear additive method).

The analytic hierarchy process (AHP) see Saaty (1980) [2], Saaty (1990) [3], Saaty (2001) [4], Saaty et al. [5] and Vargas [6], is the best known MCA process, allowing the user to measure the consistency of the preference (of relative importance of the different criteria or factors) in a formal systematic way that will reduce the complexity and subjectiveness. In this chapter consistent pairwise comparison matrix refer to a transitive, positive, square, reciprocal matrix, Saaty (1980) [2].

The AHP performs pairwise comparisons

- to calculate the relative importance of criteria;

- transforms subjective judgments into objective measures;

- to deal with complex situations by using a realistic model which "include" and "measure" all important tangible and intangible quantitatively and qualitative factors.

The reason for this study arise from South Africa's main legislative and regularity framework that dictate and define the Municipalities Internal Auditing processes and which also form part of the bigger performance management system. The relevant legislation and regulations can be summarised as follows: 
- Municipal Systems Act, 2000, Chapter 6, Section 45 requires that the results of performance measurements, be audited as part of the Municipality's Internal Auditing processes.

- The Municipal Planning and Performance Management Regulations, regulation 14 (1), 2001, of the Systems Act, states that it is the Municipality's responsibility to develop and implement mechanisms, systems and processes for the auditing of the performance measurements, as part of its internal audit processes.

- The Municipal Finance and Management Act No 56 of 2003, section 165 (2) (b) (v) requires that the Internal Audit Unit of a Municipality, report to the Audit Committee on matters relating to Performance Management.

- Performance Information Public Audit Act, Notice 464, 2007, gives the framework for managing programme performance information.

The performance committee responsibilities with respect to municipalities involve the following:

- review the quarterly reports submitted by the municipality's internal audit units;

- review the municipality's performance management system;

- assess whether the performance indicators are sufficient;

- make recommendations on the municipality's performance management system.

The following problems were encountered with the current performance management system:

1. Factors or indicators were not measurable;

2. Lack of formal processes or systems to monitor the achievement of objectives on municipality level;

3. Lack of formal processes with actions on how to address respective factors with low scores. Thus, there is a lack of specific actions to improve poor performance on a specific factor;

4. Lack of formal penalty systems with repercussions for individuals because of performance reports that are late or never submitted or because of poor performance;

5. Traceable data or source documentation, hence a transparent measuring process with accurate, reliable and valid factor scores;

6. Lack of substantial reasons for non-performance.

To solve these problems, criteria and factors (i.e. Key Performance Indicators) must not be determined or manipulated by municipalities. A scientific process must be followed in the determination of criteria and factors and there must be different factors for different municipalities. Therefore a municipality class may depend on the size and function of the city or town. The scoring process is currently too simplistic (only three outcome levels) with too many factors to be measured and the analysis process is insufficient. Currently the analysis process gives an overall score without pointing out the strong and weak points of each municipality. To sidestep manipulation of data and information, monthly data and source documentation must be given to an external agency which then must calculate, monitor and measure the performance of each municipality. Hence, each municipality must only know the criteria on which they will be measured but the respective factor definitions that will be used and how each factor is calculated must be unknown to the municipalities. 
In this chapter the author will create a user-friendly scorecard that can be used by local municipalities (LM) to optimise the application of land use and transportation integration goals and objectives on a local municipal (LM) level. There is a need for land use and transportation integration due to the

- fragmented urban form;

- long commuting times;

- high travelling cost.

\section{METHODOLOGY}

Koski et al. [7] reduces the number of original objective functions by grouping the objective functions into sets i.e. criteria with common characteristics; by doing so the main goal (proxy by objectives) is broken down into criteria which are evaluated in terms of their respective factors. The different criteria can be measured and its application and functionality assessed in terms of its respective factors.

The methodology applied is to use a vector optimisation method to determine how to optimise the different criteria which are linked to the milestones of land use and transportation integration. Note that this chapter is an extension of the work done by Schoeman in [8] where the author only considered steps 1 to $4 \mathrm{~b}$ ) in the Methodology given in Fig. 1.

\subsection{The applicable criteria and factors}

Manual [9], United Nations [10] and Niven [11] provide the following guidance applicable to the assessment characteristics for any set of criteria, factors or Key Performance Indicators (KPI):

- broad in coverage of all aspects of land use and transportation integration but also mutually disjoint (i.e. no double counting) and of good quality; For more information on mutually disjointness refer to Appendix A.

- relationship to the milestone;

- data on these criteria or factors must be available and easily obtainable;

- usable or relevant on local municipality level for land use and transportation integration;

- measurable in a clear and understandable qualitative or quantitative way.

Schoeman [8] identified the applicable objectives as densification, mixed land use activities, the enforcement of land use and traffic policies, accessibility, mobility and centralised data on transportation and land use including the applicable GIS files. These objectives satisfy the above properties for the realisation of land use and transport integration on local municipality level.

Next, follows the definitions of the respective factors for the alternative criteria. Note that some of these definitions differ from the ones defined by Schoeman [8] which is due to adjustments made during the scoring stage when problems (like mutual dependence or inaccessible data) were discovered.

Let the binary value (BV) function of the variable $X_{i}$ be given as

$$
B V\left(X_{i}\right)=\left\{\begin{array}{lll}
1 & \text { if } \quad X_{i}=\text { Yes } \\
0 & \text { if } \quad X_{i}=\text { No }
\end{array}\right.
$$

(1) For the criterion density the following factors were considered 


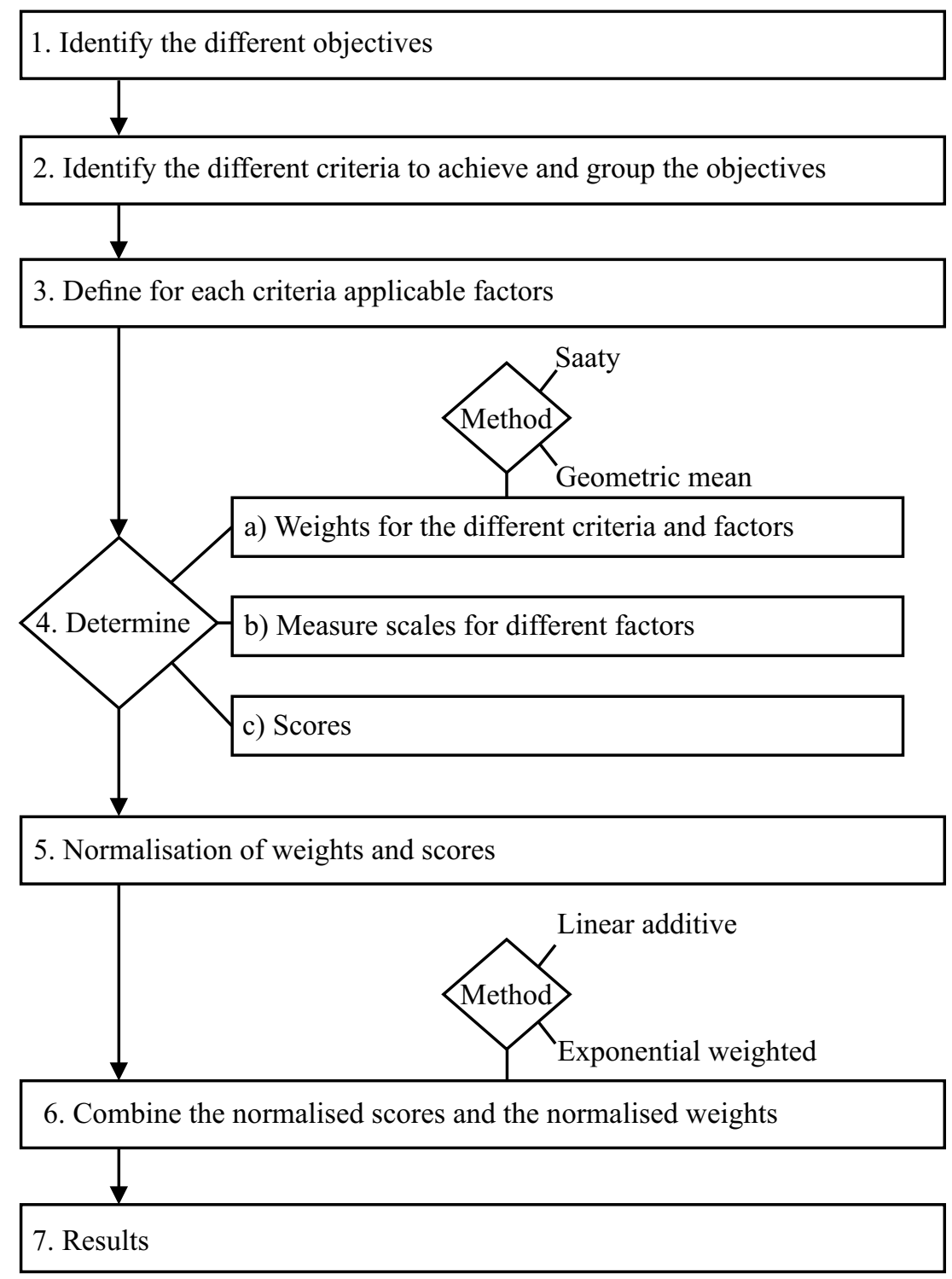

Figure 1: Methodology for the vector optimisation method. (Source: own construction.)

(1.1) Gini concentration ratio (GCR) of the neighbourhoods in the local municipality. This measure is adapted from the work of Gini [12] where it was mainly used in economics for the comparison of the income distribution of different nations. In this chapter the Gini concentration ratio is used to describe the distribution of the urban population in the different residential neighbourhoods in relation to the area. Hence, this ratio will be the instrument which will contribute to the development of sustainable and resilient urban neighbourhoods by constraining too much sprawling and also constraining neighbourhoods that are too compact 
in comparison with the other. The GCR is calculated as follows

$$
\begin{aligned}
G C R & =\frac{\sum_{i=1}^{n}\left(Y_{i+1} X_{i}\right)-\sum_{i=1}^{n}\left(X_{i+1} Y_{i}\right)}{10000} \\
Y_{i} & =\text { Cumulative area proportion of each residential neighbourhood; } \\
X_{i} & =\text { Cumulative population proportion of each residential neighbourhood; } \\
n & =\text { The \# of residential neighbourhoods in the local municipality. }
\end{aligned}
$$

With the factor classification defined as

$$
S_{G i n i}=\left\{\begin{array}{l}
\text { - Maximal inequality among } \\
\text { the neighbourhoods densities; } \\
\text { Penalty function }=1-G C R \\
\text { - Complete equality among } \\
\text { the neighbourhoods densities } \\
\text { Penalty function }=1-G C R
\end{array} \quad G C R=0 .\right.
$$

From this classification it follows that if the GCR converges to zero, the better the density criteria of a city, therefore the penalty function was used to transform these values to a scale corresponding with consistent meaning among the scores of the different factors where scores that converge to one implies a positive effect on land use and transport integration and scores that converge to zero implies a less positive or no contribution to land use and transport integration.

(1.2) The Employment-population density of the local municipality. The proxy for this factor is the Employment rate defined as the proportion of the working-age population that is employed (see StatsSA [13]).

(2) The criterion enforcement of land use and transport (LUT) policies

(2.1) Integration of the three spheres of government (IG) factor.

Let IDP be the Integrated Development Plan of the applicable municipality and define $S_{\text {integration }}=\sum_{i=1}^{5} B V\left(X_{i}\right)$ where

$X_{1}=$ Linkages in the planning between the 3 spheres of government and also the IDP;

$X_{2}=$ Linkages in the projects between the 3 spheres of government and also the IDP;

$X_{3}=$ Linkages in the budgets between the 3 spheres of government and also the IDP;

$X_{4}=$ Integrated monitoring of expenditure on all three spheres of government;

$X_{5}=$ Integrated monitoring if programs/projects are finished on time and within projected budget.

Hence, the IG factor was classified in terms of the value of $S_{\text {integration }}$ i.e.

$$
I G_{\text {factor }}=\left\{\begin{array}{lll}
1 & \text { if } & S_{\text {integration }}=5 \\
0.75 & \text { if } & S_{\text {integration }}=4 \\
0.5 & \text { if } & S_{\text {integration }}=3 \\
0.25 & \text { if } & S_{\text {integration }}=2 \\
0.1 & \text { if } & S_{\text {integration }}=1
\end{array}\right.
$$


(2.2) Database factor $\left(S_{D}\right)$ :

Let

$$
S_{\text {database }}=\sum_{i=1}^{5} B V\left(Z_{i}\right)
$$

for the evaluation of the database on LM level. Consider if the LM database has the following properties

$$
\begin{aligned}
Z_{1}= & \text { Consistently updated and accessible to the public; } \\
Z_{2}= & \text { Integrated database between the various spheres of government; } \\
Z_{3}= & \text { Contain GIS data on transport network and time series data } \\
& \text { on transport demand; } \\
Z_{4}= & \text { Contain GIS and time series data on land use; } \\
Z_{5}= & \text { Contain GIS and time series data on engineering services. }
\end{aligned}
$$

Furthermore, the range of the rating scale for the Database factor is given the value

$$
S_{D}=\left\{\begin{array}{lll}
1 & \text { if } & S_{\text {database }}=5 \\
0.75 & \text { if } & S_{\text {database }}=4 \\
0.5 & \text { if } & S_{\text {database }}=3 \\
0.25 & \text { if } & S_{\text {database }}=2 \\
0.1 & \text { if } & S_{\text {database }}=1
\end{array}\right.
$$

(3) For the criterion accessibility. The authors in Nicolai et al. [14] consider the following accessibility variables for developed countries (i.ethe accessibility variables used in UrbanSim \& MATSim):

(1) Travel cost (monetary value);

(2) Travel distance;

(3) How affordable the rent or bond payments are;

(4) Congestion levels;

(5) Travel time.

In Chapter 3 of this book the authors argued that in developing countries where a large proportion of the households are poor, travelling cost is the most important accessibility variable and travel time the least important. Also, the affordability of rent or bond payment were not considered as an accessibility variable since this is not applicable on developing low-income study area where most of the houses are RDP-housing or informal housing.

Hence, the factors for developing countries considered under the accessibility criteria are as follows

(3.1) Travel Cost (TC) which is measured as average daily travelling cost (\% of income) for the applicable city or town; Let PC be the average provincial travel cost $\%$ and $\mathrm{NC}$ be the average national travel cost $\%$. Then

$$
S_{T C}=\left\{\begin{array}{lll}
1 & \text { if } T C \stackrel{5 \% \text { or more }}{<}(P C \text { and } N C) ; \\
0.75 & \text { if } T C \stackrel{\text { less than } 5 \%}{<}(P C \text { and } N C) ; \\
0.5 & \text { if } T C \stackrel{5 \% \text { or more }}{<}(P C \text { or } N C) ; \\
0.25 & \text { if } T C \text { less than } 5 \%(P C \text { or } N C) \\
0.1 & \text { if } T C>(P C \text { and } N C) .
\end{array}\right.
$$


Therefore, if the travel cost for Tlokwe $=18 \%$, the North West Province travel cost $=15 \%$ and the average National Travel cost is equal to $20 \%$. It follows from this information that

$$
P C \stackrel{3 \%}{<} T C \stackrel{2 \%}{<} N C
$$

Hence, $S_{T C}=0.25$. Note that ideally the monthly household transport expenditure should be less than $10 \%$ of income, but with the majority of the working population in South Africa classified as low income earners this percentage is only a dream.

(3.2) Public transport (referring to minibus taxi, train or bus) usage $=$

$$
\frac{\text { Public transport usage in LM area }}{\text { Population in LM area }}
$$

(3.3) Average distance between residential neighbourhoods and area of employment $:=d(\operatorname{Res}$, work $)$. Consider the average proximity to work from various informal residential neighbourhoods.

$$
d(\text { Res }, \text { empl })=\left\{\begin{array}{lll}
1 & \text { if } \quad d(\text { Res }, \text { work })<2.5 \mathrm{~km} ; \\
0.75 & \text { if } \quad d(\text { Res }, \text { work }) \in[2.5 \mathrm{~km} ; 5 \mathrm{~km}) \\
0.5 & \text { if } \quad d(\text { Res }, \text { work }) \in[5 \mathrm{~km} ; 7.5 \mathrm{~km}) \\
0.25 & \text { if } d(\text { Res }, \text { work }) \in[7.5 \mathrm{~km} ; 10 \mathrm{~km}] \\
0.1 & \text { if } \quad d(\text { Res }, \text { work })>10 \mathrm{~km} .
\end{array}\right.
$$

These scale intervals for the different factors originate from the Guideline of the Department of Public Service and Administration see DPSA [15] but are much more refined;

(3.4) Travel Times $(\mathrm{TT})=$ Average total travel time (i.e. walking, waiting and time travelling) per day for/on public transport; Let PV be the average provincial travel time value for the applicable public transport mode and $\mathrm{NV}$ the applicable national value. Then

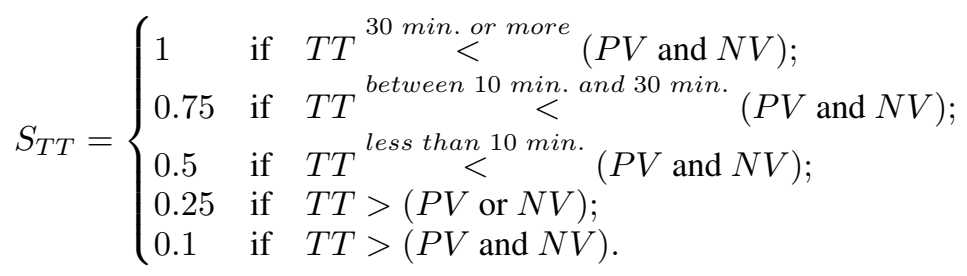

(4) For the criterion mobility consider

(4.1) Average traffic congestion levels

The scale intervals for the average (peak hour) traffic congestion i.e. volumes to capacity (i.e. $V / C$ ) ratio, follows from the guidelines given in any Traffic Engineering Manual.

$$
\text { Congestion level }= \begin{cases}1 & \text { if } \quad \operatorname{Avg}(V / C)<0.9 ; \\ 0.75 & \text { if } \operatorname{Avg}(V / C) \in[0.9 ; 0.94) \\ 0.5 & \text { if } \operatorname{Avg}(V / C) \in[0.94 ; 1.00) \\ 0.25 & \text { if } \operatorname{Avg}(V / C) \in[1.00 ; 1.5) \\ 0.1 & \text { if } \quad \operatorname{Avg}(V / C) \geq 1.5\end{cases}
$$


(4.2) Forecasted (15-year) traffic congestion value

The 15-year forecasted average peak hour $V / C$ ratio (i.e. $\mathbf{E}(V / C)$ ). To calculate the forecasted congestion levels, use the population growth rates and data on the modal selection.

$$
\text { Forecasted congestion levels }=\left\{\begin{array}{lll}
1 & \text { if } & \mathbf{E}(V / C)<0.9 ; \\
0.75 & \text { if } & \mathbf{E}(V / C) \in[0.9 ; 0.94) \\
0.5 & \text { if } & \mathbf{E}(V / C) \in[0.94 ; 1.00) \\
0.25 & \text { if } & \mathbf{E}(V / C) \in[1.00 ; 1.5) \\
0.1 & \text { if } & \mathbf{E}(V / C) \geq 1.5
\end{array}\right.
$$

(4.3) Road safety (RS). This is measured by considering the number of fatalities per 1000 inhabitants in LM area per annum. Note that the South African per annum road fatalities $=\frac{0.22 \text { fatalities }}{1000 \text { inhabitants }}$ and Australia's per annum road fatalities $<\frac{0.036 \text { fatalities }}{1000 \text { inhabitants }}$ (see Iaych et al. [16]).

$$
R S= \begin{cases}1 & \text { if } \quad \text { fatalities per } 1000 \text { inhabitants }<\frac{0.06}{1000} ; \\ 0.75 & \text { if } \quad \text { fatalities per } 1000 \text { inhabitants } \in\left[\frac{0.06}{1000} ; \frac{0.09}{1000}\right) ; \\ 0.5 & \text { if } \quad \text { fatalities per } 1000 \text { inhabitants } \in\left[\frac{0.09}{1000} ; \frac{0.12}{1000}\right) ; \\ 0.25 & \text { if } \quad \text { fatalities per } 1000 \text { inhabitants } \in\left[\frac{0.12}{1000} ; \frac{0.15}{1000}\right] ; \\ 0.1 & \text { if } \quad \text { fatalities per } 1000 \text { inhabitants }>\frac{0.15}{1000} .\end{cases}
$$

The different ratios in the intervals coincide with the ratios in the classes used to compare the road fatalities in the world.

2.2 The weights of the respective criteria and factors

The different (criteria and factors) weights were determined from literature and by using the prioritisation procedures of Saaty and the Row Geometric Mean Method (RGMM).

\section{A summary of Saaty's method, constructed from the work of De Jong [17], Saaty (1977) [18], Saaty (1980) [2], Saaty (1984) [19], Saaty (1990b) [20], Saaty (2005) [21] and Tomashevskii (2015) [22] (see Appendix B for the iterative algorithm):}

(1) Saaty's scale for the starting preferences (i.e. the starting values, $a_{i j}, \forall i, j \in[1 ; m]$ of matrix $A$ ) are given in Table 1 . These values describe the priority (order) of the (current and future) contribution (costs, benefits and risk) of the relevant criteria (or factors) to the objectives, which are determined using applicable literature (i.e. articles, policies and legislation) and if necessary surveys (public participation input) and interviews with experts.

From the starting priorities the reciprocal, square, positive, $(m \times m)$ Analytic Hierarchy Process (AHP) matrix,

$$
A=\left\{a_{i j}\right\} \text { with } i, j \in[1 ; m]
$$

is calculated. Note that $A$ is calculated using $m[m-1] / 2$ pairwise comparisons in determining the importance of the different criteria or factors.

(2) Determine $\lambda_{\max }$ the largest eigenvalue of $A$. 
Table 1: Saaty's scale of the starting preferences.

\begin{tabular}{ll}
\hline $\begin{array}{l}\text { Starting priority } \\
\text { value }\end{array}$ & Description of score \\
\hline$\frac{1}{9}$ & Extremely lower contribution \\
$\frac{1}{8}$ & Very, very lower contribution \\
$\frac{1}{7}$ & Demonstrated lower contribution \\
$\frac{1}{6}$ & Strongly plus lower contribution \\
$\frac{1}{5}$ & Strongly lower contribution \\
$\frac{1}{4}$ & Moderately plus lower contribution \\
$\frac{1}{3}$ & Moderately lower contribution \\
$\frac{1}{2}$ & Weakly lower contribution \\
1 & Equal contribution \\
2 & Weakly higher contribution \\
3 & Moderately higher contribution \\
4 & Moderately plus higher contribution \\
5 & Strong or essential contribution \\
6 & Strong plus contribution \\
7 & Demonstrated contribution \\
8 & Very, very strong contribution \\
9 & Extremely important contribution \\
\hline
\end{tabular}

(3) Calculate the values for the weights given by the eigenvector, w such that $A \mathbf{w}=$ $\lambda_{\max } \mathbf{w}$.

(4) Normalise the weights.

(5) To restrict the inconsistency and the subjectiveness of the judgements (or comparisons or preferences) Saaty derived the restriction of the contradictories in the form of the Consistency Ratio $\left(C R_{m}\right)$ which is defined in terms of the Random Consistency Index $\left(R C I_{m}\right)$ values which depend on the dimension, $(m \times m)$ of matrix $A$. By using a random generated sample of size 500 Saaty derived the following values

$$
R C I_{m} \stackrel{[2]}{=}\left\{\begin{array}{l}
0.58 \text { if } m=3 \\
0.90 \text { if } m=4 \\
1.12 \text { if } m=5 \\
1.24 \text { if } m=6 \\
1.32 \text { if } m=7
\end{array}\right.
$$

with

$$
C R_{m}=\frac{\frac{\lambda_{\max }-m}{m-1}}{R C I_{m}}
$$

Use Saaty's Consistency Ratio to test if $A$ is consistent enough (c.e.)

$$
A=\left\{\begin{array}{l}
\text { c.e. if } C R_{3} \leq 0.05 \text { or } C R_{4} \leq 0.08 \text { or } C R_{5} \leq 0.1 \text { or } C R_{6} \leq 0.2 \\
\text { inconsistent otherwise } \Rightarrow \text { revise A. }
\end{array}\right.
$$


Note from Saaty (1977) [18] that $A$ is perfectly consistent if $\lambda_{\max }=m$ and $C R_{m}=0$ or if $A$ is transitive i.e.

$$
a_{i k}=\frac{a_{i r}}{a_{k r}}, \forall i, k, r \in[1, m] .
$$

A summary of Row Geometric Mean Method (RGMM) constructed using Aguarón et al. [23], Crawford et al. [24] and Tomashevskii (2014) [25]:

Note that the Row Geometric Mean Method is also known as the Logarithmic Least Squares Method.

(1) Determining the importance of the different criteria or factors by calculating $A$ a reciprocally symmetric AHP matrix (see Appendix B).

(2) The normalized weights of geometric mean method is given by

$$
w^{*}=\left[\overline{x_{1}}, \overline{x_{2}}, \ldots, \overline{x_{m}}\right]^{t}
$$

with

$$
\overline{x_{k}}=\frac{\left(\prod_{j=1}^{m} a_{k j}\right)^{\frac{1}{m}}}{\sum_{i=1}^{m}\left(\prod_{j=1}^{m} a_{i j}\right)^{\frac{1}{m}}}, \quad k=1,2, \ldots, m .
$$

(3) Test if $A$ is consistent enough by considering the Row Geometric Consistency Index (RGCI) see Crawford et al. [24] given by

$$
R G C I=\frac{2 \cdot \sum_{i<j}^{m} \log ^{2}\left(a_{i k} \frac{\overline{x_{k}}}{\bar{x}_{i}}\right)}{(m-1)(m-2)} .
$$

Here,

$$
A=\left\{\begin{array}{l}
\text { consistent enough if } R G C I \leq \text { Threshold }_{R G C I} \\
\text { inconsistent otherwise } \Rightarrow \text { revise A. }
\end{array}\right.
$$

From Aguarón et al. [23] follows the following threshold values for the RGCI in the special case where $\overline{x_{i}}=\left(\prod_{j=1}^{m} a_{k j}\right)^{\frac{1}{m}}, k=1,2, \ldots, m$ in formula (1)

$$
\text { Threshold }_{R G C I}=\left\{\begin{array}{l}
0.314 \text { if } m=3 \& C R=10 \% \\
0.352 \text { if } m=4 \& C R=10 \% \\
0.37 \text { if } m>4 \& C R=10 \% \\
0.1573 \text { if } m=3 \& C R=5 \% \\
0.1763 \text { if } m=4 \& C R=5 \% \\
0.185 \text { if } m>4 \& C R=5 \% \\
0.0314 \text { if } m=3 \& C R=1 \% \\
0.0352 \text { if } m=4 \& C R=1 \% \\
0.037 \text { if } m>4 \& C R=1 \%
\end{array}\right.
$$

If $A$ is inconsistent then it entails numerical errors, $\Delta w_{i}$ of the weights, $w_{i}$.

Since the actual numerical errors are unknown the following problems exist with Saaty's method and the RGMM (see Tomashevskii (2015) [22], Tomashevskii (2014) [25], Bana et al. [26], Barzilai [27], Bozoki et al. [28], Johnson et al. [29], Karapetrovic et al. [30], Kwiesielewicz et al. [31] and Monsuur [32]):

- Rank reversal problem, i.e. the order of the weights calculated by Saaty method and RGMM differ; 
- Right-left asymmetry i.e. $A \underline{\mu}=\lambda_{\max } \underline{\mu} \quad \& \quad \underline{x} A=\lambda_{\max } \underline{x} \quad \nRightarrow \underline{\mu}=\underline{x}$;

- Both methods are sensitive to outliers.

From Tomashevskii (2015) [22] and Tomashevskii (2014) [25] follows the following solutions to the above problems:

- Take the numerical errors also into account in the ordering of the weights therefore consider the ranking intervals, where

$$
\text { ranking interval }:=\text { normalised weight } \pm \text { numerical errors. }
$$

- The ranking intervals must be mutually disjoint. Note that Tomashevskii (2014) [25], made a mistake in the calculation of the errors in his example. To see this consider the well-known hyperbolic identity $\cosh ^{2} x-\sinh ^{2} x=1$ from this follows that $\left(w_{i}\right)^{2}-\left(\Delta w_{i}\right)^{2}=\left(w_{i}^{*}\right)^{2}\left\{\left(\operatorname{ch} \Delta_{i}\right)^{2}-\left(s h \Delta_{i}\right)^{2}\right\}=\left(w_{i}^{*}\right)^{2}$. Apply this identity to the values (which follows from eqns (14) and (15) in Tomashevskii (2014) [25]) in the example will lead to a contradiction.

\section{Improved Method I: Combining Tomashevskii solutions and Saaty's method using Matlab (see Appendix C):}

(1) Calculate the reciprocal square positive, $(m \times m)$ Analytic Hierarchy Process matrix,

$$
A=\left\{a_{i j}\right\} \text { with } i, j \in[1 ; m]
$$

with starting values

$$
a_{i j} \in\left\{\frac{1}{9} ; \frac{1}{8} ; \frac{1}{7} ; \frac{1}{6} ; \frac{1}{5} ; \frac{1}{4} ; \frac{1}{3} ; \frac{1}{2} ; 1 ; 2 ; 3 ; 4 ; 5 ; 6 ; 7 ; 8 ; 9\right\} .
$$

Determine the starting priority (i.e. the order given by the usually inconsistent starting priority matrix) (see Appendix D).

Example: criterion $_{m}<$ criterion $_{2}<\cdots$.

Use the iterative algorithm (see Appendix B for the Matlab code) to improve (by using Saaty's idea) the consistency of the comparisons in the case of an inconsistent evaluation matrix, $A$. Calculate the end priority (i.e. the order given by the sufficiently consistent matrix). The decision maker must decide whether to adopt the sufficiently consistent matrix or not, by comparing the starting priorities and the end priorities.

(2) Compute the values for the weights given by the eigenvector, w such that $A \mathbf{w}=$ $\lambda_{\max } \mathbf{w}$, with $\lambda_{\max }$ the largest eigenvalue of $A$.

(3) Let $\bar{z}=\left[z_{1}, \ldots, z_{m}\right]^{t}$ be the corresponding normalised weights (eigenvector) associated with $\lambda_{\max }$.

(4) Determine $\bar{\delta}:=\left[\delta_{1}, \delta_{2}, \ldots, \delta_{m}\right]^{t}$ where

$$
\delta_{i} \stackrel{[25]}{=} \sqrt{\frac{1}{(m-1)(m-2)} \sum_{k=1}^{m}\left(\frac{a_{i k} m z_{k}}{\lambda_{\max }}-z_{i}\right)^{2}}, \quad i=1, \ldots, m
$$

are the error terms of Saaty's method. See Appendix E for the evaluation of this formula.

(5) Consider the intervals $\mathbf{w}_{S}=\bar{z} \pm \bar{\delta}$. Mutually disjoint intervals, imply reliable weights. 


\section{Improved Method II: Combining Tomashevskii solutions and the Row Geometric Mean Method using Matlab:}

(1) Calculate the consistent enough reciprocal square positive, $(m \times m)$ Analytic Hierarchy Process matrix, $A$ (see Appendix B). Also, compute the starting and end priorities (as in Appendix D).

(2) Calculate the values of the normalised weights

$$
\overline{x_{k}}=\frac{\left(\prod_{j=1}^{m} a_{k j}\right)^{\frac{1}{m}}}{\sum_{i=1}^{m}\left(\prod_{j=1}^{m} a_{i j}\right)^{\frac{1}{m}}}, \quad k=1,2, \ldots, m .
$$

(3) To eliminate all the problems it follows from the work of Tomashevskii [25] that it is better to consider $\mathbf{w}=\left[w_{1}, w_{2}, \ldots, w_{m}\right]^{t}$ with

$$
w_{i}=\overline{x_{i}} \cdot\left(\frac{e^{\Delta_{i}}+e^{-\Delta_{i}}}{2}\right)=\overline{x_{i}} \cosh \left(\Delta_{i}\right)
$$

where

$$
\Delta_{i}=\sqrt{\frac{1}{(m-1)(m-2)} \sum_{k=1}^{m} \log ^{2}\left(a_{i k} \frac{\overline{x_{k}}}{\overline{x_{i}}}\right)} .
$$

Let $\varepsilon=\left[\varepsilon_{1}, \varepsilon_{2}, \ldots, \varepsilon_{m}\right]^{t}$ be the RGMM errors, with

$$
\varepsilon_{i}=\overline{x_{i}} \cdot\left(\frac{e^{\Delta_{i}}-e^{-\Delta_{i}}}{2}\right)=\overline{x_{i}} \sinh \left(\Delta_{i}\right)
$$

where

$$
\Delta_{i}=\sqrt{\frac{1}{(m-1)(m-2)} \sum_{k=1}^{m} \log ^{2}\left(a_{i k} \frac{\overline{x_{k}}}{\overline{x_{i}}}\right) .}
$$

(4) Now, let the interval $\mathbf{w}_{R G M M}=\mathbf{w} \pm \varepsilon$.

$$
\text { Test }_{\text {Mutually disjointness }}=\left\{\begin{array}{l}
\text { Yes } \Rightarrow \text { reliable weights } \\
\text { No } \Rightarrow \text { unreliable weights }
\end{array}\right.
$$

For the calculation of the weights for the criteria the following Analytic Hierarchy Process (starting) matrix was used:

$\begin{array}{ccccc} & \text { Access } & \text { Mobility } & \text { Density } & \text { LUT } \\ \text { Access } & 1 & 1 & 2 & 3 \\ \text { Mobility } & 1 & 1 & 1.5 & 2.5 \\ \text { Density } & 0.5 & 0.67 & 1 & 1.5 \\ \text { LUT } & 0.34 & 0.4 & 0.67 & 1\end{array}$

From the Improved Method II follows the mutually disjoint intervals:

$$
\text { [0.3512;0.3697], [0.3117; 0.3293], [0.1894;0.1979] and [0.1245;0.127]. }
$$

Hence, the criteria weights in Table 2 are reliable. The same path was followed in the determination of the factor weights. 
Table 2: Weights.

\begin{tabular}{lll}
\hline Criteria and factor(s) & Norm. criteria weights & Norm. factor weights \\
\hline 1. Density & 0.19 & \\
1.1 Gini concentration ratio & & 0.1 \\
1.2 Employment-population & & 0.09 \\
2. Enforcement of LUT policies & 0.13 & \\
2.1 Integration & & 0.065 \\
2.2 Database & & 0.065 \\
3. Accessibility & 0.36 & \\
3.1 Travel Cost & & 0.211 \\
3.2 Public transport usage & & 0.070 \\
3.3 d(Res, Work) & & 0.059 \\
3.4 Travel Time & & 0.020 \\
4. Mobility & 0.32 & \\
4.1 Congestion & & 0.119 \\
4.2 Forecasted congestion & & 0.118 \\
4.3 Road safety & & 0.083 \\
\hline
\end{tabular}

The main reason for the choice of these accessibility and mobility criteria, factor weights (AHP starting matrix) follows from Chapter 3 of this book where the authors argue that in a developing country (with large proportion of low income households) like South Africa (with $65 \%$ of low income households in Census 2011, [33]) where travelling cost weighs much more heavily than congestion levels and travelling times.

The study area used to calculate the scores consisted of Tlokwe municipality a service, academic, agricultural and industrial municipality with a population of 162762 divided into 52537 households see South African Census 2011, [33] data. Tlokwe municipality is situated $120 \mathrm{~km}$ South West of Johannesburg in the North-West Province of South Africa.

\subsection{The normalised scores of the different (criteria and factors)}

In this chapter when referring to the measure scales of scores remember that different kind of data can be measured on different scales.

To summarise this consider the following measure scales for data:

- Qualitative data:

- Zero point scale. Example: $---/ 0 /+++$

- Nominal (no order) scale. Example: female and male.

- Ordinal (order) scale.

- Binary scale. Example: yes or no.

- Quantitative data:

- interval scale;

- ratio scale.

Both the factor weights (see Table 2) and the factor scores (see Table 3) should be normalised such that they are dimensionless. Different methods can be used to normalise data or the 
Table 3: Factors scores

\begin{tabular}{lll}
\hline Criteria and factor(s) & Normalised scores & Source of scores \\
\hline 1. Density & & \\
1.1 $S_{\text {Gini }}$ & 0.3729 & Census data \\
1.2 Employment-Population & 0.3174 & Census data \\
2. Enforcement of LUT policies & & \\
2.1 $I G_{\text {factor }}$ & 0.25 & Tlokwe LM interview \\
2.2 $S_{D}$ & 0.1 & Tlokwe LM interview \\
3. Accessibility & & \\
3.1 $S_{T C}$ & 0.25 & Surveys and census \\
3.2 Public transport usage & 0.5978 & Traffic survey \\
3.3 d(Res,work) & 0.1 & Traffic survey \\
3.4 $S_{T T}$ & 0.5 & Surveys \\
4. Mobility & & \\
4.1 Congestion & 0.5 & Traffic survey \\
4.2 Forecasted congestion & 0.25 & Traffic growth rates \\
4.3 RS & 0.1 & Census \\
\hline
\end{tabular}

dependent variable in which case the well-known statistical Box-Cox transformation may be used. To normalise data the normalisation method used depends on the measure scales of the data.

The connection between the normalisation methods and the measure scales:

- Quantitative Measure Scales: $\frac{\text { Score-Min. Score }}{\text { Max. Score-Min. score }}$ or by division by a constant, where the constant can be the maximum score, the $l^{\infty}$ norm or the $l^{2}$ norm.

- Qualitative Measure Scales: Here an applicable transformation function can be used to transform the qualitative data to the interval, $[0 ; 1]$. For example, the Zero point scale, qualitative data $---/ 0 /+++$ can be transformed to the respective values $0 ; \frac{1}{6} ; \frac{2}{6} ; \frac{3}{6} ; \frac{4}{6} ; \frac{5}{6} ; 1$.

In the analysis step the different normalised factor weights are combined (using mathematical routines, which may be written into computer programmes) with the respective normalised factor scores to form a single ranking function. Furthermore, the respective ranking functions are used as the values scored by the applicable local municipality on the scorecard.

Next, consider examples of analytic methods to be used for the combination of these two components, refer to Marler et al. [1] for more technical detail:

- Linear additive method:

- Weighted Tchebycheff method;

- Weighted global criterion method;

- Weighted min-max method;

- Exponential weighted method;

- Weighted product method;

- Goal programming method;

- Bounded objective function method. 
Table 4: Analysis using different methods.

\begin{tabular}{lll}
\hline Criteria and factor(s) & $\begin{array}{l}\text { Linear } \\
\text { additive method }\end{array}$ & $\begin{array}{l}\text { Exponential } \\
\text { weighted method }\end{array}$ \\
\hline 1. Density & 0.0659 & 0.282 \\
1.1 Gini concentration ratio & 0.0373 & 0.153 \\
1.2 Employment-Population & 0.0286 & 0.129 \\
2. Enforcement of LUT policies & 0.0228 & 0.1605 \\
2.1 Integration & 0.0163 & 0.086 \\
2.2 Database & 0.0065 & 0.074 \\
3. Accessibility & 0.1046 & 0.467 \\
3.1 Travel Cost & 0.0528 & 0.302 \\
3.2 Public transport usage & 0.0418 & 0.132 \\
3.3 d(Res,work) & 0.0059 & 0.067 \\
3.4 Time Travelling & 0.01 & 0.033 \\
4. Mobility & 0.0973 & 0.465 \\
4.1 Congestion & 0.0595 & 0.208 \\
4.2 Forecasted congestion & 0.0295 & 0.161 \\
4.3 Road safety & 0.0083 & 0.096 \\
\hline
\end{tabular}

- Lexicographic method.

In Table 4 only two of these analytic methods were used, namely the Linear additive method and the Exponential weighted method. With the Linear additive method it is impossible to obtain all points on the non-convex portions of the Pareto optimal set therefore, the Exponential weighted method was also required to capture points on the non-convex portions of the Pareto set.

Let $k_{i}$ denote the number of applicable factors of criteria $i$ and $p$ be equal to the total number of criteria (as in Appendix E).

Then by using the Linear additive method the ranking of the applicable Local Municipality (i.e. the total score on the scorecard) is determine by the summation over all the criteria rankings, say $R_{C_{i}}$ where

$$
R_{C_{i}}=\sum_{j=1}^{k_{i}} \text { normalised weight of factor } \text { f }_{j} * \text { normalised score of factor } \text { f }_{j} .
$$

Hence, the

$$
\text { Ranking of the applicable Local Municipality }=\sum_{i=1}^{p} R_{C_{i}} .
$$

Furthermore, for the Exponential weighted method:

$$
R_{C_{i}}=\sum_{j=1}^{k_{i}}\left[\exp ^{\text {normalised weight of factor }}{ }_{j}-1\right] * \exp ^{\text {normalised score of factor }_{j}} .
$$

The above analytic methods can be used to rank the different criteria, factors and local municipalities and thereby determine the weak and strong points of each local municipality. 
Table 4 gives an example where these analytic methods were applied to Tlokwe Local Municipality, but this table must be extended to include comparison with local municipalities that are comparable.

\section{CONCLUSIONS}

The chapter illustrated the use of vector optimisation methods in land use and transportation modelling. This is supported by the development and application of a scorecard to measure the integration between land use and transportation. This is a simplified way using predetermined criteria with application of predetermined weights to describe and assess this relationship. It provides a simplified way to improve, manage and assess the interface between various municipalities on a local, regional and national level. In this manner land use and transport integration for various sizes of cities may be compared. This provides an opportunity to assess present relationships as well as to predict future relationships based on specific planning proposals. The model is very dynamic as it may be adapted through refinement of the scorecard depending on the area within a spatial system where it is applied. The framework illustrates the application of basic mathematical and modelling principles and consists of a framework where no or limited access to modelling software exists.

\section{ACKNOWLEDGEMENT}

The author gratefully acknowledges the National Research Foundation (GUN No. 81221) for financial support.

\section{APPENDIX A: MUTUALLY DISJOINT}

From any statistical textbook it follows that the matrix $X$ is perfectly multicollinear if one of the columns of matrix $X$ is an exact linear function of one or more of the other columns, i.e. the columns of $X$ are linearly dependent. Therefore if criteria are linearly dependent, one criterion can be expressed as an exact linear function of one or even all of the other criteria. In reality every AHP matrix will contain some degree of multicollinearity because of some degree of correlation among the criteria which follows from the "consistent enough" property. Thus, we must identify whether the degree of multicollinearity in the AHP matrix is sufficiently low as to guarantee an inexact linear relationship (imperfect multicollinearity) between the criteria i.e. mutual disjointness between the criteria. For example an imperfect linear relationship between criterion $C_{1}$ and criterion $C_{2}$ imply there is a random non-zero error term $e$ such that

$$
C_{1}=C_{2}+e
$$




\section{APPENDIX B: THE ITERATIVE ALGORITHM}

This is an improvement, extension and adaptation to Matlab of the general work done by Peters et al. [34].

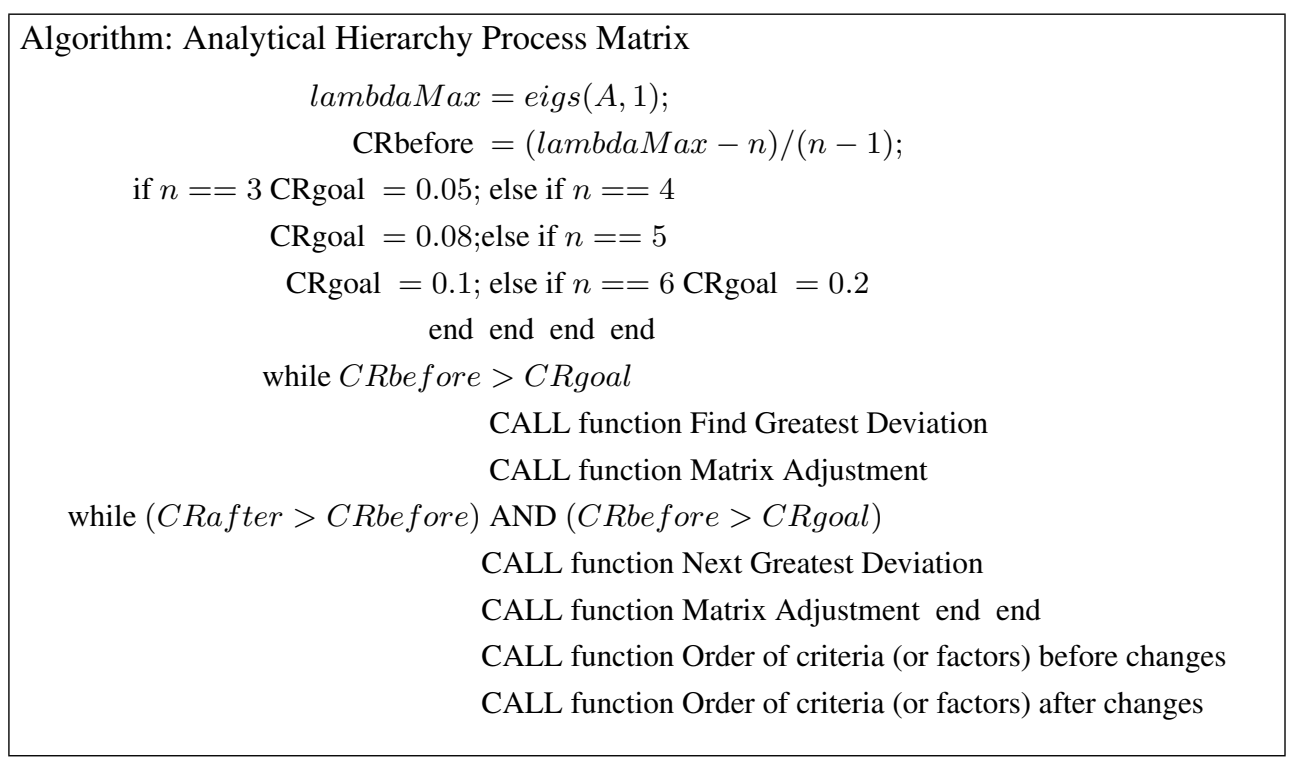

$$
\begin{aligned}
& \text { function Find Greatest Deviation } \\
& a=\operatorname{size}(A, 1) ; t=a^{a}+1 ; c g=z \operatorname{eros}(1, t) ; \operatorname{aij} \operatorname{Corr}=z \operatorname{eros}(a, a) ; \operatorname{cgmax}=0 ; \\
& \text { for } i=1: a \text { for } j=1: a \text { for } k=1: a \\
& \operatorname{aijCorr}(i, j)=A(i, k) * A(k, j) ; c g(h)=\operatorname{abs}(A(i, j)-\operatorname{aijCorr}(i, j)) \text {; } \\
& \text { if }(c g(h)==\max (c g)) \text { AND }(c g(h)>c g \text { max }) \\
& \operatorname{cgmax}=\max (c g) ; \max i=i ; \max k=k ; \max j=j ; \text { end } \\
& h=h+1 ; \text { end end end end }
\end{aligned}
$$


86 Transportation, Land Use and Integration: Perspectives for Developing Countries

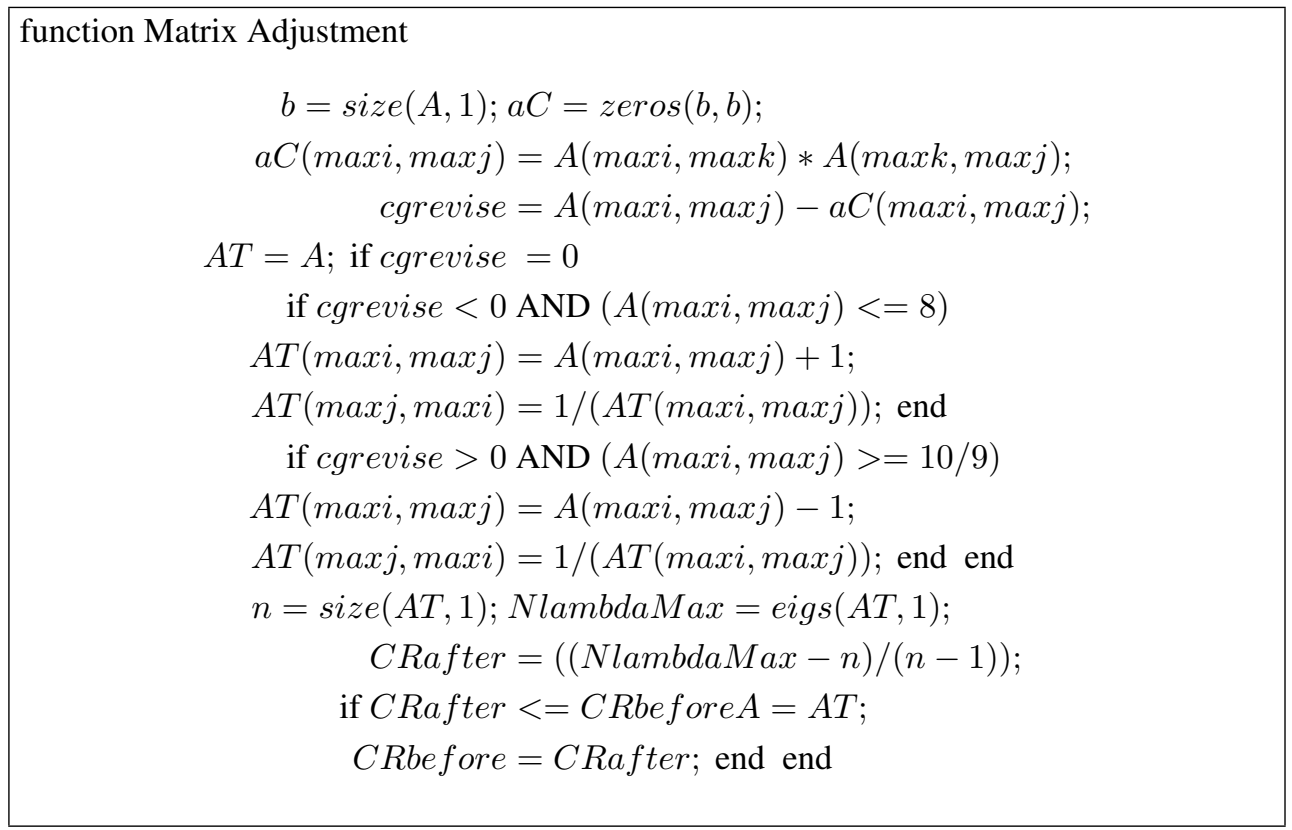

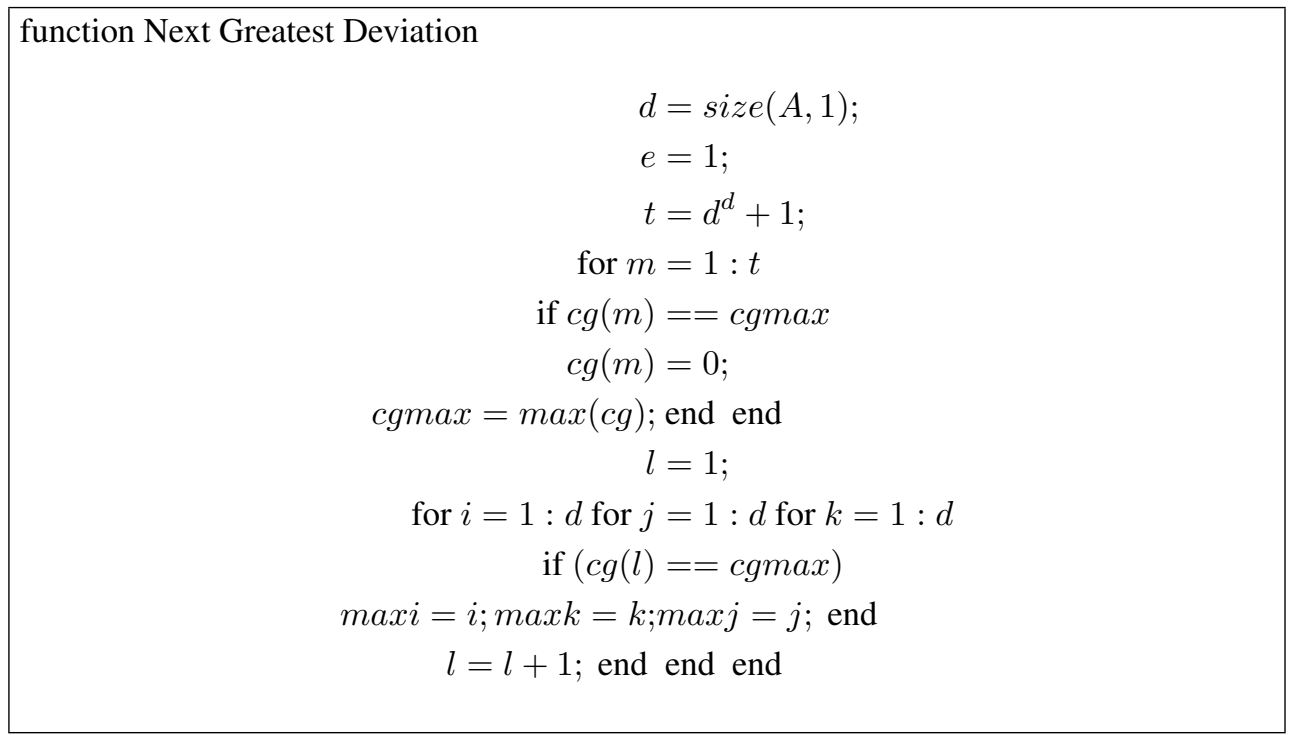




\section{APPENDIX C: IMPROVED METHOD I}

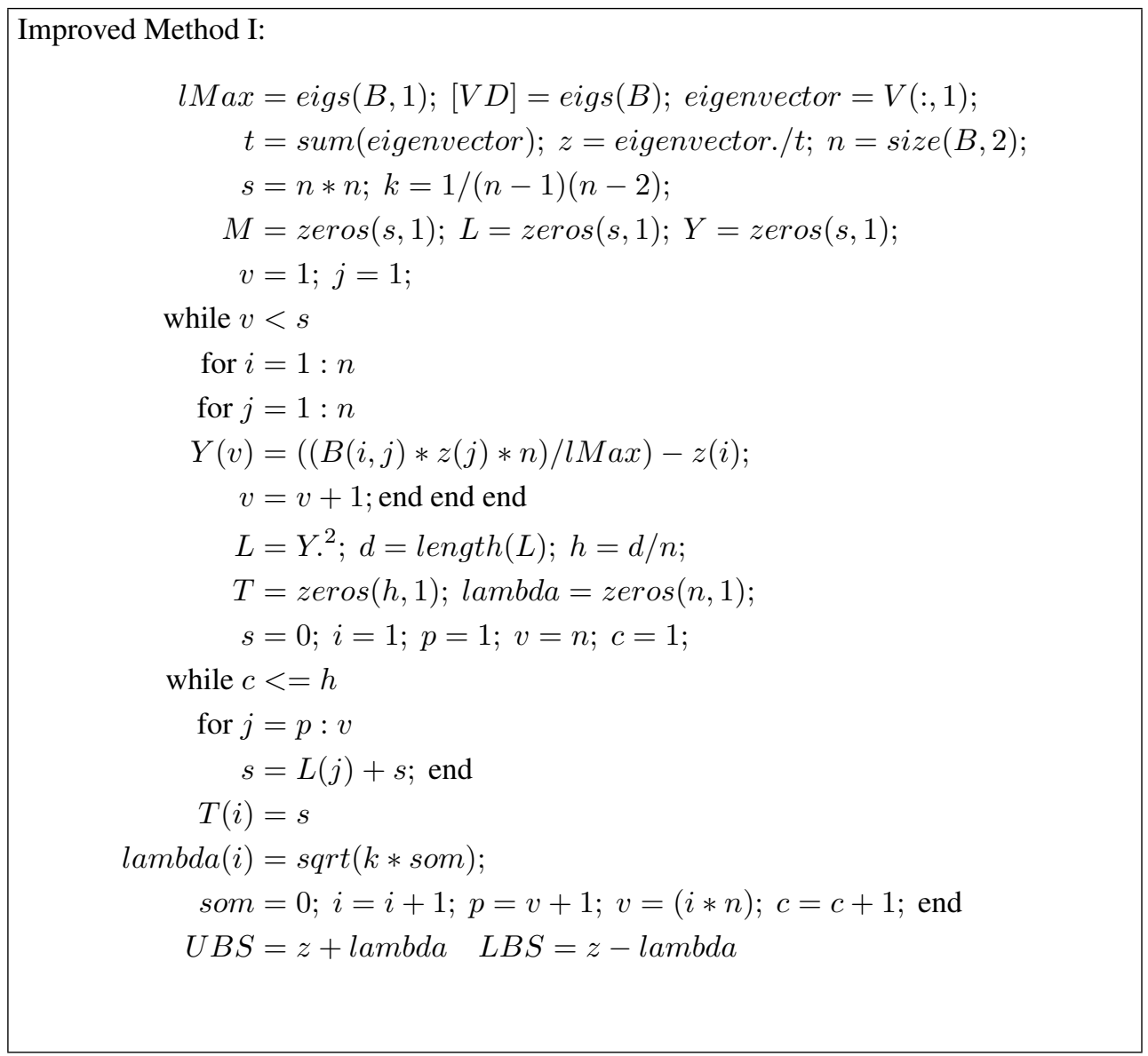


APPENDIX D: DETERMINING THE STARTING AND END PRIORITIES

function Order of criteria (or factors) before changes

$$
\begin{aligned}
p & =1 ; \\
\text { while } p & <=w \\
\text { for } r & =1: n \\
\text { if } \operatorname{sumR} R(p) & ==\operatorname{sortRB}(r) \\
\operatorname{order} R b(p) & =r ; \text { end end } \\
p & =p+1 ; \text { end }
\end{aligned}
$$

order $R b$

function Order of criteria (or factors) after changes

$$
\begin{aligned}
p & =1 ; \\
\text { while } p & <=w \\
\text { for } r & =1: n \\
\text { if } \operatorname{sumRa}(p) & ==\operatorname{sortRa}(r) \\
\operatorname{order} \operatorname{Ra}(p) & =r ; \text { end end } \\
p & =p+1 ; \text { end } \\
\text { orderRa } &
\end{aligned}
$$

APPENDIX E: THE EVALUATION OF THE ERROR FORMULA

$a_{i j}:=$ Denote how many times the $i$-th criteria (factor) is more important than the $j$-th criteria (factor);

$m:=$ Total number of (independent) factors;

$p:=$ Total number of (independent) criteria $\Rightarrow p<m$;

$k_{i}:=$ The number of factors for criteria $i$,

$$
\Rightarrow\left[\sum_{i=1}^{p} k_{i}\right]=m, \quad \Rightarrow k_{i}<m, \forall i \in[1, p] ;
$$

$w_{i}^{(j)}:=$ The weight of the $j$-th factor of criteria $i, \quad j \in\left[1, k_{i}\right], i \in[1, p]$;

$w_{i}:=$ The weight of criteria $i, \quad \Rightarrow \sum_{j=1}^{k_{i}} w_{i}^{(j)}=w_{i}, \forall i \in[1, p]$.

Then

$$
1:=\sum_{i=1}^{p} w_{i}=\sum_{i=1}^{p} \sum_{j=1}^{k_{i}} w_{i}^{(j)}=\sum_{i=1}^{p} \sum_{j=1}^{m} w_{i}^{(j)} .
$$


Now, let

$$
\begin{aligned}
\operatorname{mean}\left(w_{i}\right) & :=\mu_{i}=\frac{1}{k_{i}} \sum_{j=1}^{k_{i}} w_{i}^{(j)}, \quad \forall i \in[1, p], \\
\text { standard deviation }\left(w_{i}\right):=\triangle \mu_{i} & =\sqrt{\frac{1}{k_{i}-1} \sum_{j=1}^{k_{i}}\left(w_{i}^{(j)}-\mu_{i}\right)^{2}} .
\end{aligned}
$$

Now, to determine the criteria weights consider

$$
\begin{gathered}
A \underline{\mu}=\lambda_{\max } \underline{\mu} \\
\Leftrightarrow \quad A\left[\begin{array}{c}
\mu_{1} \\
\vdots \\
\mu_{p}
\end{array}\right]=\lambda_{\max }\left[\begin{array}{c}
\mu_{1} \\
\vdots \\
\mu_{p}
\end{array}\right] \\
\Leftrightarrow \quad \sum_{j=1}^{p} a_{i j} \mu_{j}=\lambda_{\max } \mu_{i}, \quad \forall i=1, \ldots, p \\
\Leftrightarrow \quad \frac{\sum_{j=1}^{p} a_{i j} k_{i} \mu_{j}}{\lambda_{\max }} \stackrel{(\mathrm{E} .2)}{=} \sum_{j=1}^{k_{i}} w_{i}^{(j)} \quad \forall i \in[1, p] \\
\Leftrightarrow \quad \frac{a_{i j} k_{i} \mu_{j}}{\lambda_{\max }}=w_{i}^{(j)} \quad \forall i \in[1, p], \quad \forall j \in\left[1, k_{i}\right] .
\end{gathered}
$$

Therefore, eqn (E.3) can be written as

$$
\triangle \mu_{i}=\sqrt{\frac{1}{k_{i}-1} \sum_{j=1}^{k_{i}}\left(\frac{a_{i j} k_{i} \mu_{j}}{\lambda_{\max }}-\mu_{i}\right)^{2}}, \quad \forall i \in[1, p] .
$$

From the work of Tomashevskii (see [22]) it follows that the errors of the inconsistent pairwise comparison matrices is given by eqn (E.4).

\section{REFERENCES}

[1] Marler, R.T. \& Arora, J.S., Review of Multi-Objective Optimisation Concepts and Methods for Engineering. Technical Report Number ODL-01.01, University of Iowa, Optimal Design Laboratory, Iowa City. IA, 2003.

[2] Saaty, T.L., The Analytic Hierarchy Process, McGraw Hill: New York, 1980.

[3] Saaty, T.L., How to make a decision: the analytic hierarchy process. European Journal of Operational Research, 48(1), pp. 9-26, 1990.

[4] Saaty, T.L., Decision Making for Leaders, RWS Publications: Pittsburgh, PA, 2001.

[5] Saaty, T.L. \& Vargas, L.G., Models, Methods, Concepts and Applications of the Analytic Hierarchy Process, Kluwer Academic Publishers: Boston, MA-Dordrecht-London, 2001.

[6] Vargas, L.G., An overview of the analytic hierarchy process and its applications. European Journal of Operational Research, 48(1), pp. 2-8, 1990.

[7] Koski, J. \& Silvennoinen, R., Norm methods and partial weighting in multicriterion optimisation of structures. International Journal for Numerical Methods in Engineering, 24(6), pp. 1101-1121, 1987, DOI:10.1002/nme.1620240606. 
[8] Schoeman, I.M., Determination and ranking of integration measures for land use and transportation applications, Urban Transport XXI. WITpress, pp. 15-25, 2015.

[9] Department for Communities and Local Government. Multi-criteria analysis: a manual. Available at www.communities.gov.uk, pp. 35-39, 2009.

[10] United Nations. Indicators of Sustainable Development: Guidelines and Methodologies, United Nations: New York, 2007.

[11] Niven, P.R., Balanced Scorecard Step by Step for Government and Non-profit Agencies, John Wiley and Sons: New York, 2003.

[12] Gini, C., Variabilità e mutabilità ("Variability and Mutability"), C. Cuppini: Bologna, 1912. Reprinted in Memorie di metodologica statistica, ed. E. Pizetti and T. Salvemini, Libreria Eredi Virgilio Veschi: Rome, 1955.

[13] Stats SA, Gender Series Volume I: Economic Empowerment, 2001-2014 Report, http://beta2.statssa.gov.za/publications/Report-03-10-04/Report-03-10-042014.pdf.

[14] Nicolai, T.W. \& Nagel, K., Coupling transport and land-use: Investigating accessibility indicators for feedback from a travel to a land use model. Presented at Latsis Symposium 2012 - 1st European Symposium on Quantitative Methods in Transportation Systems, Lausanne, Switzerland, 2012,

http://www.sustaincity.org/publications/SCCI_Coupling_Transport_and_Landuse.pdf

[15] The Department of Public Service and Administration, Republic of South Africa. Guideline: Improving geographic access to government service points. Available at www.dpsa.gov.za.

[16] Iaych, K. Alexeev, V. \& Latipov, O., IRF World Road Statistics. Geneva, Swizterland: International Road Federation (IRF), 2009, www.arrivealive.co.za/documents/March\%202011\%20Road\%20Traffic\%20Report.pdf.

[17] De Jong, P., A statistical approach to Saaty's scaling method for priorities. Journal of Mathematical Psychology, 28, pp. 467-478, 1984.

[18] Saaty, T.L., A scaling method for priorities in hierarchies, multiple objectives and fuzzy sets. Journal of Mathematical Psychology, 15(3), 1977.

[19] Saaty, T.L. \& Vargas, L.G., Comparison of eigenvalue, logarithmic least square and least square methods in estimating ratio. J. Math. Model., 5, pp. 309-324, 1984.

[20] Saaty, T.L., Eigenvector and logarithmic least squares. European Journal of Operational Research, 48, pp. 156-159, 1990.

[21] Saaty, T.L., Theory and Applications of the Analytic Network Process, RWS Publications, 2005.

[22] Tomashevskii, I.L., Eigenvector ranking method as a measuring tool: Formulas for errors. European Journal of Operational Research, 240, pp. 774-780, 2015.

[23] Aguarón, J. \& Moreno-Jiménez, J.M., The geometric consistency index: Approximated thresholds. European Journal of Operational Research, 147, pp. 137-145, 2003.

[24] Crawford, G. \& Williams, C., A note on the analysis of subjective judgement matrices. Journal of Mathematical Psychology, 29, pp. 387-405, 1985.

[25] Tomashevskii, I.L., Geometric mean method for judgement matrices: formulas for errors. Optimization and Control, submitted.

[26] Bana e Costa, C.A. \& Vansnick, J.-C., A critical analysis of the eigenvalue method used to derive priorities in AHP. Eur. J. Oper. Res., 187, pp. 1422-1428, 2008.

[27] Barzilai, J., Deriving weights from pairwise comparison matrices. J. Oper. Res. Soc., 48, pp. 1226-1232, 1997.

[28] Bozóki, S. \& Rapcsák, T., On Saaty's and Koczkodaj’s inconsistencies of pairwise comparison matrices. J. Global Optim., 42, pp. 157-175, 2008. 
[29] Johnson, C., Beine, W. \& Wang, T., Right-left asymmetry in an eigenvector ranking procedure. J. Math. Psychol., 19, pp. 61-64, 1979.

[30] Karapetrovic, S. \& Rosenbloom, E., A quality control approach to consistency paradoxes in AHP. Eur. J. Oper. Res., 119, pp. 704-718, 1999.

[31] Kwiesielewicz, M. \& van Uden, E., Inconsistent and contradictory judgements in pairwise comparison method in AHP. Comput. Oper. Res., 31, pp. 713-719, 2004.

[32] Monsuur, H., An intrinsic consistency threshold for reciprocal matrices. Eur. J. Oper. Res., 96, pp. 387-391, 1997.

[33] South African Census 2011, http://www.statssa.gov.za.

[34] Peters, M.L. \& Zelewski, D., A heuristic algorithm to improve the consistency of judgements in the Analytical Hierarchy Process. Arbeitsbericht Nr. 18. Available at https://www.pim.wiwi.uni-due.de/en/forschung/publications/a-heuristic-algorithm-toimprove-the-consistency-of-judgments-in-the-analytical-hierarchy-process-a-4441/. Accessed on: 29 March 2017. 